\title{
O Sagrado na poesia de Hölderlin, sob o olhar de Heidegger: entre o poetizar e o pensar
}

\section{The sacred in Hölderlin's poetry under the gaze of Heidegger: between thinking and poeticizing}

DOI: $10.12957 /$ ek.2015.21650

Dnda. Lis Helena Aschermann Keuchegerian

liskeuch@hotmail.com

PUC-Rio

Segundo Heidegger o homem se encontra em uma fenda, a qual o filósofo denomina de espaço-entre. Nesta dimensão, o estranho, a finitude e o Sagrado dispõem as várias arestas em torno do homem. Desta forma o Sagrado aparece não como aquilo que falta, mas como o que se mantém resguardado e procurado. O originário permanece no movimento/ jogo de velar e desvelar, mas não está mais circunscrito pelas ausências e deficiências, recorrentes em Ser e tempo, e sim pela relação destes conceitos. Tal dinâmica é muito bem expressa nas poesias que Heidegger discute em seus textos. Em diversos momentos ele destaca Höldelin como o poeta do Sagrado e a partir da sua poesia o filósofo lança seu olhar sobre o tema.

PALAVRAS-CHAVE Sagrado. Hölderlin. Heidegger.

According to Heidegger, man finds himself in a gap, which the philosopher calls the 'between'. From this dimension uncannyness, finitude and the sacred set several limits around man. As such, the sacred does not appear as something lacking, but as what remains sheltered and sought. The origin remains in the movement of concealing and revealing, but is not characterized anymore, like in Being and Time, by absence and deficiencies, but by the relation of these concepts. Those dynamics are very well expressed in the poems that Heidegger discusses in his writings. At different times he highlights Hölderlin as the poet of the sacred and from the perspetive of his poetry he reflects on the theme. 
Em uma entrevista concedida à revista alemã Der Spiegel, em 1966, a qual Heidegger apenas autorizou publicação póstuma, o filósofo falou de sua relação com a poesia de Hölderlin, de quem ele toma o conceito de 'habitar poético':

O meu pensamento mantém uma relação incontornável com a poesia de Hölderlin. Hölderlin não era para mim um poeta qualquer, cuja obra se resume como tantas outras, a um objecto de estudo para historiadores da literatura. Hölderlin é o poeta que indica o futuro, que espera o deus $(\ldots)^{1}$

Neste trecho da entrevista o filósofo certifica a importância do pensamento de Hölderlin em sua filosofia. É o poeta que insere a imagem do céu, a imagem do Sagrado, mas também é quem mostra a dimensão poética e sua relação com a existência do homem. A dimensão poética para Heidegger é justamente o lugar deslocado do homem, o espaço entre (entre céu e terra) que em outros momentos aparece como rasgo. A dimensão poética, por sua vez, está intrinsecamente ligada ao habitar: "Dimensão é o elemento em que o habitar humano tem seu sustento, é onde adquire sustentação e duração. O levantamento de medida constitui o poético do habitar." (HEIDEGGER,2006, p.173).

Heidegger fala que o homem confere a medida de seu habitar com o divino, mostrando a proximidade do homem com o céu sobre ele, ou ainda, com tudo o que este céu representa. Não é apenas o poeta que, em sua relação diferenciada com a linguagem, habita poeticamente, mas o homem. $\mathrm{O}$ "poeticamente" que Heidegger anuncia tem uma proporção mais ampla que o termo Poesie, trata-se do termo Dichtung: o “...poeticamente habita o homem...” é a tradução de “... dichterisch wohnen der Mensch...". Dichtung tem um sentido abrangente e significa também de reunir, colher e criar. Nesse sentido, de criar e reunir, o termo alemão carrega em si o aspecto desvelador e nomeador da poesia, originário como aquilo que é nomeado pela primeira vez.

No prefácio da obra Explicações da poesia de Hölderlin, onde Heidegger reúne seis ensaios escritos entre 1936 e 1968, o filósofo afirma que a poesia de Hölderlin tece sua obra abordando essencialmente o Sagrado. Nesse contexto, a ideia de pátria está ligada à terra alemã, e em especial à Suévia, o antigo nome

$1 \mathrm{http} / /$ pt.scribd.com/doc/128244662/MARTIN-HEIDEGGER-Entrevista-Der-Spigel - acessado em 03/07/2014 
da terra germânica. Desse modo o filósofo deixa claro que a pátria é uma referência ao originário, ou seja, está muito além de qualquer tema relacionado ao patriarcado. $\mathrm{O}$ uso do termo Suévia mostra essa busca pela proximidade à origem. O que Heidegger esquadrinha a partir das poesias de Hölderlin - das quais se sobressaem duas em especial, A migração e $A$ chegada à casa/aos parentes - é a essência da pátria a partir do modo como o poeta a nomeia: "a mais antiga, mais própria, ainda oculta, mas desde o começo disponível no mais alto grau" (HEIDEGGER,2013, p.31).

Essa definição da pátria que a mostra a um só tempo oculta e disponível "no mais alto grau" é um tanto inquietante. Sob o olhar de Heidegger, a poesia $A$ chegada a casa/ aos parentes, não sobressalta o familiar que rodeia a margem da terra natal, ao contrário, ele afirma: "De fato, essa chegada à costa domiciliar já é bastante estranha. (...) Coisas e pessoas da pátria dão uma impressão de familiaridade. Mas não são ainda familiares. Elas ainda escondem o que é próprio no mais alto grau. " (HEIDEGGER,2013, p.21).

A partir desse trecho Heidegger propõe uma interlocução com outra poesia de Hölderlin, A migração. Essa última se inicia também suscitando a Suévia ${ }^{2}$, ressalta o custo que é abandonar o lugar "que vive perto da origem" e, ao mesmo tempo em que apresenta essa raiz originaria e seu valor, também considera igualmente importante a essência dos poetas "livres como andorinhas". O abandono do lugar de origem se faz necessário para que haja regresso:

Só pode retornar quem, previamente e talvez por muito tempo, carregou sobre os ombros, como peregrino, o fardo da peregrinação, e alcançou a origem, para então experimentar, como buscante, o que era para ser buscado, e regressar, mais experiente. (HEIDEGGER, 2013, p.33)

A pátria aparece como reservada, difícil de conquistar e o regressante surge como aquele que permanece à procura. Justamente por esse caráter reservado, a pátria é depois denominada como tesouro, simbolizando essa permanente procura. Essa mesma busca constante também circunda o Sagrado, como veremos mais adiante. Trata-se do que permanece digno de ser buscado através dos tempos. Há uma dimensão poética que, segundo Benedito Nunes (1999), apresenta a palavra na perspectiva de seu poder nominativo e na ligação entre o cultivo e

2 Em algumas traduções termo aparece como Suábia. 
a construção. Assim sendo, o termo tesouro, reconduzido ao Sagrado e à pátria, designa o caráter de resguardo e de cultivo dos mesmos. Na habitação humana o cultivo é também aquilo que merece ser pensado e re-pensado diante da historicidade e mesmo da cultura.

A dimensão poética para Heidegger aparece em diversos momentos como o lugar deslocado do homem. Isso é visível na ideia de "espaço entre" (entre céu e terra) retirada de um outro texto em que o filósofo tece seu pensar através da poesia de Hölderlin, ou ainda na ideia de rasgo, também recorrente nos textos do filósofo alemão.

Quanto ao habitar poético devemos observar que para Heidegger o homem não habita apenas organizando e interpretando, mas poeticamente. Vale salientar que "poeticamente" não é uma qualidade adicionável ao habitar, mas sim, uma qualidade essencial, conforme ilustra Heidegger: "As palavras 'poeticamente o homem habita...' dizem muito mais. Dizem que é a poesia que permite ao habitar ser um habitar." (HEIDEGGER, 2006, p.167). Se o habitar para o filósofo é essencialmente poético (Dichtung), assume-se que esta é uma noção ontológica que apresenta a disposição de estar aberto, de levantar os olhos ao céu que representa o mistério resguardado, de perceber-se diante, ou sob, a estranheza. A estranheza, em seu descolamento do habitual tem o caráter de abertura e de clareira. Ela é intrínseca ao poético que sai deste fluxo pré-determinado através da escuta ou deste "olhar ao céu", que é um desviar o olhar da disposição do familiar. Um outro ponto a ser levantado acerca da estranheza do poético é o rompimento que ela gera no cotidiano, ao mesmo tempo que ela traz o homem para seu modo mais originário, ela o desvincula de seu modo contínuo, modo este que costumamos chamar de rotineiro, e o coloca diante daquilo que é pela primeira vez ou diante do encoberto. O habitar poético é justamente estar nesta projeção do inesperado, o que se acessa na estranheza é o inesperado e a descoberta.

\section{Habitar poeticamente nos dias de hoje: uma possibilidade?}

Quando pensamos na expressão "dias de hoje" em Heidegger, rapidamente somos levados a uma expressão do filósofo que define seu olhar crítico para o mundo contemporâneo: "a questão da técnica". Quanto ao habitar, retomemos a questão: "E nós habitamos poeticamente? Parece que habitamos sem a menor poesia." (Heidegger, 2006 p. 179). Em seguida ao vincular todo habitar ao modo 
poético ${ }^{3}$ conclui que se habitamos só pode ser poeticamente. É possível dizer que não habitamos? Com a técnica deixamos de habitar? Para compreender essas questões devemos analisar a resposta de Heidegger acerca da essência da técnica.

Heidegger define a técnica, inicialmente, como atividade ou instrumento. Paralelamente, o autor demonstra as diferenças entre a técnica moderna e a técnica artesanal mais antiga a partir de algo comum a ambas: a técnica é sempre uma forma de desencobrimento. Quanto ao fazer artesanal, para apresentar este modo Heidegger usa os conceitos gregos tekne e poiesis, trata-se de um descobrimento onde o homem se faz ouvinte ao cultivar aquilo que transforma. Já a técnica moderna apresenta um desencobrimento explorador conforme o próprio Heidegger a define:

A energia escondida na natureza é extraída, o extraído vê-se transformado, o transformado estocado, distribuído, o distribuído, reprocessado. Extrair, transformar, estocar, distribuir, reprocessar são todos modos do desencobrimento. Todavia, este desencobrimento não se dá simplesmente. Tampouco, perde-se no indeterminado. Pelo contrário, o desencobrimento abre para si mesmo suas próprias pistas, entrelaçadas numa trança múltipla e diversa. Por toda parte, assegura-se o controle. Pois controle e segurança constituem até as marcas fundamentais do desencobrimento explorador.

(HEIDEGGER,2006, p.20)

Nesse texto, a saber, A questão da técnica, de 1954, não é propriamente sobre a técnica que Heidegger pretende discursar, mas acerca da essência das coisas. Ele pergunta pela essência da técnica e assegura que sua resposta não é técnica, ou seja, a questão sobre a essência da técnica é de outra natureza. Mais adiante Heidegger nos diz: “(...) a técnica é a fatalidade de nossa época, onde fatalidade significa o inevitável de um processo inexorável e incontornável. " (HEIDEGGER,2006, p.28) Nesse contexto, Heidegger fala sobre o perigo, mas também diz que a técnica não nos "tranca numa coação obtusa" que gera a necessidade de uma condenação ou ataque a ela, mas esse perigo traz em si um apelo de libertação.

3 Conforme a seguinte citação: "em sua essência, o habitar é poético" (HEIDEGGER, 2006, p.173) 
Com isso, Heidegger, mantendo o jogo de cobrir e desencobrir, traz um olhar crítico para a técnica moderna que é a marca do seu tempo. Instrumentalizar, manipular e controlar são as ações próprias da modernidade, e essas atividades, por serem tão processuais, mediadas e utilitárias, tornam o desencobrimento fragmentado. Não deixam espaço para a pergunta pelo Ser, ou ainda para o habitar poético. O filósofo apresenta o habitar poético como uma carência. Heidegger, nesse sentido, questiona:

E nós habitamos poeticamente? Parece que habitamos sem a menor poesia. Se é assim, será mentirosa e não verdadeira a palavra do poeta? Não. A verdade de suas palavras se confirma da maneira mais inacreditável. Pois um habitar só pode ser sem poesia porque, em sua *essência, o habitar é poético. (HEIDEGGER, 2006, p.179)

Há ainda no cerne desta questão a ideia de controle. Se por um lado o mundo contemporâneo, o qual Heidegger caracteriza como mundo da técnica, parece querer dar conta de tudo que o cerca, tornando as coisas e a própria natureza útil e manipulável, por outro lado o habitar é apresentado a partir da estranheza e do sentimento de deslocamento do qual o homem parece estar sempre fugindo. A estranheza e a angústia aparecem como uma possibilidade de configuração de mundo que não se dá pela manipulação ou controle e que possibilita a singularidade do homem. O mundo da técnica realça o encobrimento da estranheza e do habitar poético, que aparecem cada vez mais velados neste mundo de incessantes novidades e distrações.

Em seu texto “...poeticamente o homem habita..." o filósofo nos apresenta a essência da imagem: "deixar ver alguma coisa", ou ainda "deixar ver o invisível". Este último é possível através da imagem da fisionomia do céu. A poesia fala através de imagens as quais permitem o que é estranho ser visualizado não através de uma interferência, mas de uma escuta.

É importante frisar que ao compor a imagem de céu e terra através da poesia de Hölderlin o pensador alemão não pretende fazer desses elementos uma contraposição. Conforme ele mesmo destaca, a impressão é de que o habitar poético tem a função de arrancar os homens da terra, parecendo que o poético pertence ao reino da fantasia. Segundo Heidegger o habitar poético é o habitar esta terra: 


\begin{abstract}
Assim, Hölderlin não somente protege o poético contra a sua incompreensão usual corriqueira, mas, acrescentando as palavras "esta terra", remete para o vigor essencial da poesia. A poesia não sobrevoa e nem se eleva sobre a terra a fim de abandoná-la e pairar sobre ela. É a poesia que traz o homem para a terra, para ela, e assim o traz para um habitar. (HEIDEGGER, 2006, p.169)
\end{abstract}

Deste modo, Heidegger torna transparente a diferença entre imaginações e fantasias. As imagens poéticas são imaginações: "imaginações entendidas não apenas como inclusões do estranho na fisionomia do que é familiar, mas também como inclusões passíveis de serem visualizadas. " (HEIDEGGER, 2006, p.177)

\title{
A dimensão do Rasgo: espaço-entre e quadratura.
}

Em Ser e tempo Heidegger ilustra a distinção entre as categorias "ente simplesmente dado" e os existenciais, modos de ser específicos do Dasein, demonstrando que as coisas e os homens não partilham do espaço igualmente, propondo assim uma outra via de se pensar essa questão, ou seja, a partir de um espaço ontológico que não é ordenado apenas por seus aspectos físicos. Ser-em-um-mundo está atrelado à ideia de "permanecer junto a", ou seja, demorar-se junto de alguma coisa. O ser- em é um existencial ao qual se confere a possibilidade de demorar e habitar. O termo habitar, mesmo em seu sentido usual, está relacionado com as noções de espaço e tempo. Esses dois conceitos estão em Ser e tempo, onde o tempo denota maior relevância. Posteriormente, conforme nos apresenta Malpas (2007), o filósofo ampliará e enfatizará sua exploração acerca do espaço e do lugar. $\mathrm{O}$ espaço vai surgindo gradativamente nas obras de Heidegger. Nas conferências construir, habitar, pensar e “...poeticamente o homem habita..." é possível observar muitos termos que fazem referência ao espacial: o construir, a quadratura, a dimensão, o espaço-entre, e até mesmo o habitar.

A ideia de rasgo como lugar do homem transmite uma ideia ambivalente: a um só tempo o homem parece deslocado, visto que o rasgo ou espaço entre- parece um meio entre dois lugares, ou seja, um lugar nenhum (sem referencia própriaem si), e também o espaço-entre aparece como uma dimensão que abrange céu e terra, um sob o outro, construindo essa medida do homem. A quadratura (mortais, 
divinos, terra e céu) forma as arestas da existência humana, ao homem cabe medir-se com sua finitude e com o Sagrado que está sobre ele. Do mesmo modo em que se questiona sobre o ser, sobre sua finitude, questiona e nomeia o Sagrado.

No trecho abaixo, além da importância do ditar poético para a compreensão dessa dimensão, observamos também a relação de pertencimento entre céu e terra:

Mediante o lugar que o poeta habita agora, a terra se torna novamente terra. Como edifício dos celestiais ela abriga e carrega o Sagrado, isto é, a esfera do deus. A terra só é terra enquanto terra do céu, e só enquanto age para baixo, na direção da terra é que o céu é.

(HEIDEGGER, 2006 p 180)

A terra é o lugar onde o homem vive cheio de méritos, enquanto o céu é onde se resguarda o mistério. O homem sempre se encontra em um vão, entre terra e céu, e mantém seu olhar para cima a medir-se com o céu, com o divino, na incessante busca pelo Sagrado.

Há ainda um outro texto em que Heidegger, a partir de uma outra poesia de Hölderlin - Recordação - aborda essa mesma questão. Nesse texto, proferido em 1943 em uma homenagem ao centenário da morte do poeta, ele busca responder sobre a questão do habitar a partir do termo recordação, para o qual atribui uma via dupla: o retorno e a origem, ou ainda, o fundante e o vindouro, destacando a necessidade da estranheza para o habitar poético.

O poema Recordação fala do vento nordeste, que segundo Heidegger apresenta uma abertura para o céu: "O Nordeste limpa o céu. Abre uma trilha livre e fresca para os raios e o luzir do sol" (Falta referência). Mais adiante ele aponta que esse céu levará os poetas ao estrangeiro. A partir da poesia de Hölderlin, Heidegger afirma que os "navegantes" são os poetas: "Eles devem, portanto, conhecer o céu e se acostumar a se orientar por ele. A estes "navegantes" o Nordeste mostra antecipadamente o lugar de origem, o "reino ardente do fogo do céu" e prepara-lhes a benção da partida marítima para o estrangeiro. " (HEIDEGGER, 2013, p. 101). Esse texto é especialmente importante para pensar a questão do espaço-entre (sob este céu e sobre esta terra) por reconduzir o habitar para o estrangeiro, ou como Heidegger menciona, trata-se do amor ao não familiar, de estabelecer residência onde o próprio está, no não familiar. Nas 
palavras de Heidegger: “ Eis a lei da domiciliação poética no próprio, a partir da travessia poética da estranheza (...) Para se apropriar deste próprio, precisam atravessar o que lhes é estranho. “(HEIDEGGER, 2013, p. 102).

\section{Retomando a questão do Sagrado: sobre o "sentir-se em casa"}

É comum em sua obra Heidegger apresentar o familiar e o estranho a partir das sensações "sentir-se em casa" e "não sentir-se em casa". As noções de familiaridade e de estranheza são muito recorrentes no diálogo do filósofo com a poesia, porém elas aparecem de modo muito diverso daquele apresentado em Ser e tempo. Através da poesia o familiar e o estranho são representados metaforicamente como "terra" e "céu" no seu diálogo com Hölderlin, e como A casa bem servida e o Viandante a partir da poesia de Georg Trakl. Se em Ser e tempo familiaridade e estranheza aparecem como modos distintos de ser do Dasein, apesar da estranheza manter-se velada na familiaridade, nessas outras obras essas noções aparecem uma diante da outra em constante tensão.

Se retomarmos a discussão a partir da poesia de Hölderlin, $A$ chegada à casa/ aos parentes, podemos dizer que o sentido da 'chegada a casa' eleva o aspecto de sentir-se em casa a partir da estranheza despertada pelo "alegre". Sobre a essência da chegada Heidegger nos diz:

"O aberto amigável, o iluminado, o cintilante, o resplandescente, o luzidio da pátria, vem ao encontro em uma única aparição amigável, na chegada no portal da pátria. (...) como devemos chamar esse brilho calmo, no qual tudo - coisas e pessoas - envia sua saudação àquele que procura? O que - na pátria é o mais convidativo e já vem ao seu encontro, devemos chamar pelo nome que lança sua luz sobre todo o poema "A chegada à casa" com a palavra "O alegre" (HEIDEGGER, 2013, p.23)

A segunda estrofe da poesia $A$ chegada a casa/ aos parentes faz uma enfática referência ao alegre e à alegria. $O$ termo alegre é vinculado ao Sagrado e ao poematizar, que, como vimos, segundo Heidegger, estão estreitamente interligados na poesia de Hölderlin. Na citação acima, vemos que o alegre surge da 
ideia de aberto, e claro, muitas palavras que resgatam a ideia de claridade antecedem o alegre e, em seguida, o alegre é relacionado à ideia de desimpedido:

"O desimpedido é o que teve seu espaço liberado, desembaçado, e tornado habitável. Só o claro, o desimpedido, consegue instalar outrem em seu lugar adequado. A essência do alegre está no claro que torna radiante" (HEIDEGGER,2013, p.24).

Conforme podemos conferir em Ser e tempo, 1927, Heidegger já havia antes usado as expressões "sentir-se em casa" e "não sentir-se em casa" para delinear respectivamente, o modo impróprio e o modo próprio. Já em seu ensaio sobre Hölderlin: A chegada à casa/ os parentes", 1943, a expressão "sentir-se em casa" aparece em um novo contexto já não vinculada ao modo impróprio, ao contrário, o termo "em casa" aparece como mais próprio e não possui o significado de familiaridade, mas sim deste procurado que se desvela no alegre, que é ao mesmo tempo desimpedido e reservado. É desimpedido justamente por ter esse caráter reluzente. A metáfora do tesouro, termo que o próprio Hölderlin usa em sua poesia, parece acomodar em uma mesma definição o que é oculto, próprio e disponível no mais alto grau.

Quanto à inserção do Sagrado, já explicitada, podemos notá-la nos termos que aparecem recorrentemente no texto $A$ chegada a casa/aos parentes, tais como: deuses, anjos, chegada aos alpes, Altíssimo, e inclusive, Sagrado e Deus.

O nomear poeticamente, nesse contexto, surge como algo intrinsecamente ligado ao Sagrado, pois significa deixar que o próprio Altíssimo, conforme diz Heidegger, apareça na linguagem. A linguagem mesma, na poesia, passa a carregar em si a noção do Sagrado que é por ela nomeado. Ao mesmo tempo "faltam-nos nomes Sagrados” (HEIDEGGER, 2013, p.36), não há, segundo Heidegger, palavra nomeadora para o Deus. Assim como o cantar poético, o som sem palavras das cordas também segue em busca do Altíssimo. Este aparece com o chamado sem nome e sem palavras que o nomeie. Por isso toda a ideia de Sagrado é permeada pelo "tesouro ainda reservado". Nas palavras de Heidegger:

O Sagrado aparece, de certo. O Deus, porém, permanece distante. A época do tesouro reservado é a época em que falta o Deus. A "falta" do Deus é o fundamento para 


\begin{abstract}
a falta de "nomes Sagrados". Já que ao mesmo tempo o tesouro se mantém próximo como o reservado, o Deus ausente envia sua saudação desde o aproximar-se do celeste. (HEIDEGGER,2013, p.37)
\end{abstract}

É o próprio Deus que se mantém próximo e reservado. Heidegger menciona a falta de Deus e, vale salientar, essa expressão em Heidegger é completamente diversa da morte de Deus em Nietzsche. No sentido de não tratar do abismo que o abandono dos valores religiosos causa e nem da reinvenção dos valores que o homem precisa fazer a partir de si mesmo. Até mesmo porque esse Deus mencionado por Heidegger não participa da religião cristã ou de qualquer outra.

Heidegger afirma que a falta de Deus não é uma ausência, trata-se de uma presença ausente, o que dá sentido à proximidade do resguardado. Essa ideia é muito similar ao céu que aparece como mistério em seu texto “...poeticamente o homem habita...”, também é inspirado na poesia de Hölderlin.

Retomando a questão da religião, cabe aqui esclarecer que o filósofo aponta claramente para a impossibilidade de o homem produzir um Deus para si mesmo, procurando violentamente afastar a suposta ausência, a falta de Deus, pois isso seria tão inútil quanto invocar um Deus ao qual já estavam habituados. A proximidade do Deus é determinada por sua falta. Trata-se de manter-se próximo da falta.

Não apenas os poetas, mas também os meditativos: "aqueles que meditam sobre o segredo da proximidade reservada" (HEIDEGGER,2013, p.40), suportam continuamente a falta do Deus. Esses outros são os verdadeiros parentes dos poetas, e esse parentesco se dá não pela possibilidade de nomear poeticamente, mas de meditar como poetas.

Recebido em: 03/01/2016 Aprovado em: 02/03/2016

GUZZONI, Ute. Heidegger: Space and Art. In: Natureza Humana 4 (1): 59-110. 2002

HEIDEGGER, Martin. Ensaios e Conferências.Tradução brasileira de Emmanuel Carneiro Leão. Petrópolis: Vozes. Bragança paulista: Ed Universidade São Francisco, 2006.

Ser e Tempo. Tradução brasileira de Márcia

Sá Cavalcante Schuback. Petrópolis: vozes; Bragança paulista: Ed Universidade São Francisco, 2008.

\section{Referência Bibliográfica} Ser e tempo.Tradução de Fausto Castilho. Campinas, SP: Editora da Unicamp; Petrópolis, RJ: Editora Vozes, 2012.

.Explicações da poesia de Hölderlin. Tradução de Claudia P Drucker. Brasilia, DF: Editora da Universidade de Brasilia, 2013.

.Martin Heidegger interrogado pelo hebdomanário Der Spiegel, setembro de 1966, entrevista pu- 
blicada postumamente em 31 de Maio de 1976. Trad. Alexandre Marques.

INWOOD, Michael. Dicionário Heidegger.Tradução:Luísa Buarque de Holanda. Rio de Janeiro, RJ. Ed: Jorge Zahar Editor, 2002.

MALPAS. Jef. Heidegger's Topology: being, place, world. Cambridge, Massachusetts: MIT Press, 2007.

NUNES, Benedito. Hermenêutica e poesia: opensamento poético. Belo Horizonte, MG: Editora UFMG,1999.

SARAMAGO, Lígia. A Topologia do Ser: Lugar, espaço e linguagem no pensamento de Heidegger. Rio de Janeiro, RJ: Ed. PUC-Rio, 2008 